\title{
A feminização do jornalismo sob a ótica das desigualdades de gênero
}

\author{
Thales Vilela Lelo' (iD) 0000-0002-6070-9332 \\ 'Universidade do Estado de Minas Gerais, Divinópolis, MG, Brasil. 35501-170.
}

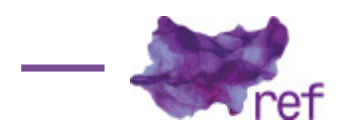

\begin{abstract}
Resumo: Não obstante a escassez de pesquisas nacionais debruçadas em elucidar as desigualdades que incidem na trajetória de mulheres jornalistas em um cenário de reestruturação das empresas de comunicação e gradual feminização das redações, também chama atenção a ausência de sistematização das instâncias nas quais se expressam tais injustiças. Amparado na literatura internacional sobre jornalismo e gênero, em dados obtidos em estudos realizados na última década no Brasil, além de resultados de relatórios e surveys focados na apreensão das condições de trabalho das mulheres jornalistas, no presente artigo se pretende operacionalizar quatro vetores de análise das desigualdades que atingem as profissionais do setor: no campo da divisão sexual do trabalho, nas culturas organizacional e profissional, e no plano das rotinas produtivas.
\end{abstract}

Palavras-chave: jornalismo; gênero; trabalho; feminização; desigualdade

The Feminization of Journalism From the Perspective of Gender Inequalities

Abstract: Notwithstanding the paucity of national researchs focused on elucidating the inequalities that affect the trajectory of women journalists in a scenario of the restructuring of communication enterprises and gradual feminization of newsrooms, it is also worth noting the lack of systematization of the instances in which such injustices are expressed. Based on an international literature on journalism and gender, in data obtained in studies carried out in the last decade in Brazil, and also in results of reports and surveys focused on the apprehension of the work conditions of women journalists, this article intends to operationalize four vectors of analysis of inequalities that affects professionals on this sector: in the field of sexual division of labor, in the organizational and professional cultures, and in the level of routines of production.

Keywords: Journalism; Gender; Work; Feminization; Inequality

\section{Introdução}

Em paralelo às transformações no mundo do trabalho dos jornalistas que vêm motivando (não sem certo tom de perplexidade) uma miríade de incursões em âmbito teórico ou empírico dedicada a apreender as nuances do fenômeno, nas últimas décadas também se assinala uma crescente feminização da profissão derivada da entrada progressiva de mulheres nas redações ao redor do globo. Se em 1995 as jornalistas representavam $28 \%$ dos profissionais do setor em perspectiva global, em 2009 esse número se elevou para 37\%, conforme Thomas HANITZSCH e Folker HANUSCH (2012). No Brasil, Paula ROCHA e Jorge SOUSA (2011) também identificaram fenômeno similar, sobretudo no período de 1986 a 2001, e justificaram-no pelo prisma da inserção gradual da mulher no mercado de trabalho.

A paulatina feminização em curso no mundo do trabalho dos comunicadores poderia representar, para a sociologia do jornalismo, a possibilidade de ultrapassar uma fase na qual os estudos eram insensíveis aos marcadores sociais de diferença (Marjan DE BRUIN, 2000). Contudo, é desolador atestar que a desejada sensibilização a estas questões nas pesquisas em jornalismo não foi devidamente correspondida. Das recentes investigações em contexto nacional que se debruçaram em apreender o alcance dos processos de reestruturação no mundo do trabalho dos comunicadores, não são raras aquelas que simplesmente ignoraram a progressiva feminização 
do setor (José HELOANI, 2005; Virgínia FONSECA, 2008; Fábio PEREIRA e Zélia ADGHIRNI, 2011 ; ADGHIRNI, 2012; Sylvia MORETZSOHN, 2014), enquanto tantas outras abordaram a questão lateralmente (Heloiza HERSCOVITZ, 2000; Cláudia LIMA, 2012; Jacques MICK e Samuel LIMA, 2013; Roseli FÍGARO, 2013; 2014). É frequente que dados que revelam assimetrias de gênero nas redações despontem ora em etapas preliminares ou como resíduo dos resultados obtidos em coleta de dados empíricos, inviabilizando correlações entre os processos de reestruturação e a feminização do jornalismo.

As especificidades dos encadeamentos entre gênero, precariedade e as transformações no mundo do trabalho dos jornalistas permanecem essencialmente latentes nesses estudos. A despeito deste intrigante fato, não se pode perder de vista que em trabalhos relativamente esparsos e ainda com menor impacto na sociologia do jornalismo nacional tais vínculos são alçados a eixo central de análise, tal como ocorre em Rocha (2007), Rocha e Sousa (2011), Márcia SILVA (2011; 2013), Thaïs JORGE e Adghirni (2013), Jorge et al. (2014), Ana TEMER et al. (2015), Marli dos SANTOS e Temer (2016) e Aline LEITE (2017).

Em algumas dessas empreitadas, expressa-se um esforço por retratar entusiasticamente a feminização nas redações como oportunidade para suplantar injustiças que historicamente acometeram as mulheres nesta esfera do mercado de trabalho, além de oferecer uma oportunidade de construção de representações menos opressivas das mulheres nas narrativas e desenvolver, na melhor das hipóteses, um estilo "feminino" de escrita jornalística, tendo supostamente o aspecto emocional como marco de diferenciação qualitativa da produção.

Contudo, se promovermos uma remissão à literatura internacional sobre jornalismo e gênero (Érik NEVEU, 2000; Béatrice DAMIAN-GAILLARD et al., 2009; Monika DJERF-PIERRE, 2011 ; HANITZSCH e HANUSCH, 2012; Linda STEINER, 2014; DAMIAN-GAILLARD e Eugénie SAITTA, 2016), rapidamente tomaremos distanciamento de hipóteses tão entusiásticas assim. A mera paridade entre mulheres e homens nas redações não conduz mecanicamente à igualdade de condições ou à isonomia das condutas organizacionais. ${ }^{1}$ Não desconsiderando a importância da igualdade e da diversidade na distribuição de posições hierárquicas, Steiner (2014) pondera que não se deve subestimar a força coerciva dos valores e ideologias profissionais que formatam jornalistas de ambos os gêneros em igual medida, conduzindo-os a tomarem decisões similares não obstante os marcadores sociais de diferença. ${ }^{2}$

A complexificação dos fatores que, combinados, promoveriam uma metamorfose nas práticas jornalísticas rumo à ampliação de oportunidades e melhoria das condições de trabalho das mulheres jornalistas também nos impele a desconfiar da tese de uma "escrita feminina" consolidada na progressiva feminização do setor. Sustentar tal premissa é supor equivocadamente que os jornalistas gozam de autonomia suficiente em suas rotinas produtivas para exercerem seu trabalho segundo os marcadores de diferença que os individualizam, outrossim, que "as mulheres desempenharão um fazer jornalístico feminino uma vez que o gênero será sua principal forma de identificação - antes de outras, tal qual o profissionalismo, a etnia..." (DAMIAN-GAILLARD et al., 2009 , p. 186). Reside nesse argumento, sobretudo, uma definição essencialista da prática jornalística atrelada a qualidades supostamente intrínsecas (e contrastantes) de gênero: empatia $x$ distanciamento, subjetividade $x$ objetividade, emoção x razão... Nos termos de Damian-Gaillard e Saitta (2016),

falar de uma escrita jornalística "feminina" é problemático porque sua definição se constrói, geralmente, segundo uma lógica dicotômica entre masculino e feminino. Esta visão binária baseia-se em definições estereotipadas de papéis de gênero e as reproduz, ajudando assim a legitimar a ideia de que alguns temas ou especializações jornalísticas seriam mais ou menos adequados a mulheres ou homens. É, portanto, difícil destacar uma prática feminina do jornalismo sem sustentar e reproduzir uma definição essencialista da mulher e do homem (p. 129).

Para as autoras, as formas de tratamento da informação jornalística geralmente identificadas sob a alcunha de "escrita feminina" se inscrevem em diferentes setores da imprensa sob práticas e lógicas diversas (e mesmo divergentes), apreensíveis sobremaneira pelos códigos e valores da cultura jornalística. ${ }^{3}$

\footnotetext{
' Subjaz nas entrelinhas desta hipótese pressuposto identificado por Steiner (2014) em pesquisas sobre cultura empresarial da década de 1970 que propunham ser necessário atingir uma "massa crítica" de mulheres em uma determinada organização para que as práticas profissionais e os mecanismos de segregação fossem automaticamente subvertidos. ${ }^{2}$ Steiner (2014) ilustra seu raciocínio retomando etnografias em redações que apontaram que, mesmo em empresas que já chegaram ao ponto de ter seu quadro de chefia totalmente preenchido por mulheres (como o Herald Tribune, em Sarasota, nos Estados Unidos), ainda assim não houve transformações substanciais em direção à equidade de gênero.

${ }^{3}$ A extensa investigação empírica empreendida por Hanitzsch e Hanusch (2012) é bastante elucidativa nesse sentido: promovendo uma enquete com 1800 jornalistas baseados em 18 países, os autores buscaram testar algumas das mais frequentes conjecturas em favor da feminização das práticas jornalísticas, ou seja, a diferenciação profissional calcada unicamente em gênero. Os resultados assinalaram que não houve discrepância entre homens e mulheres em suas formas de apreensão do jornalismo (mesmo em redações com maioria feminina em seus quadros).
} 
Não obstante, há uma semelhança entre as investigações que apresentam, ainda que subsidiariamente, dados quantitativos que sustentam um vínculo entre a paulatina feminização no mundo do trabalho dos jornalistas e a ascendente precariedade do setor e os estudos que ingenuamente pressupõem que a igualdade nas condições laborais ou, ainda, que uma completa "feminização" da cultura jornalística se dará automaticamente como consequência do ingresso massivo de mulheres nas redações: em ambas as perspectivas o gênero emerge como categoria descritiva ou substantiva (Suely KOFES, 1993; Joan SCOTT, 1995; Adriana PISCITELLI, 2002; Alinne BONETTI, 2012), ou seja, como equivalente à mulher ou à diferença sexual tal como percebida empiricamente. Desta forma (e em afinação ao diagnóstico de Monica MARTINEZ et al., 2016 de que há nos estudos em Jornalismo uma baixa articulação às preocupações teórico-analíticas oriundas dos estudos de gênero), nas investidas de escopo sociodemográfico que perfilam as condições de trabalho dos profissionais da imprensa e nas excursões que idealizam a emergência de uma "perspectiva feminina" pari passu à progressiva contratação de comunicadoras nas empresas de mídia, o gênero é tão somente um marcador de diferença dicotomicamente naturalizado por traços biológicos e sociais, circunscrito a um indicador no primeiro caso e recurso para a naturalização de papéis sociais no segundo.

Por estas razões, gostaria de adotar um tom menos otimista ao averiguar a ascendente feminização no mundo do trabalho dos jornalistas, realçando as injustiças que experimentam as mulheres ao acessarem este mercado afetado por acentuadas transformações. Essa visada é predominante também em algumas produções brasileiras (ROCHA, 2007; JORGE e ADGHIRNI, 2013; LEITE, 2017) e hegemônica na literatura internacional (DE BRUIN, 2000; 2014; NEVEU, 2000; DAMIANGAILLARD et al., 2009; Monica NILSSON, 2010; DJERF-PIERRE, 2011; STEINER, 2014), e permite-nos apreender, ademais da histórica condição de desprivilégio das mulheres nesse setor ocupacional (tal como já diagnosticado em outras categorias profissionais ${ }^{4}$ ), a proeminente precariedade experimentada pelas repórteres em face de seus colegas homens em um cenário de reestruturações nas empresas de comunicação. É evidente que em muitos destes estudos a noção de gênero ainda persiste sendo instrumentalizada por um viés descritivo, mas, como veremos, há investimentos que acionam o conceito como categoria analítica, ou seja, como "elemento constitutivo das relações sociais baseadas nas diferenças entre os sexos" (SCOIT, 1995, p. 86) e como "forma primária de dar significado às relações de poder" (idem, p. 86). No entanto, com certa frequência o deslizamento entre estas duas formas de acionar o arcabouço dos estudos de gênero não é devidamente esclarecido nesta seara de investigações, permanecendo subentendido nas pesquisas.

Frequentemente as iniquidades atreladas ao gênero dos profissionais no campo jornalístico são indicadas por meio de difusas manifestações que abrangem desde a disparidade salarial, passando pelas condições de trabalho desiguais, acesso obstruído a posições de destaque na carreira, períodos mais extensos de desemprego, até incidir nas rotinas produtivas permeadas por assédios e desrespeito. Todavia, há uma carência sensível de esforços voltados ao delineamento de um conjunto de operadores que possibilite aos pesquisadores e às pesquisadoras a sistematização dessas desigualdades quando debruçados na investigação do mundo do trabalho dos jornalistas (desigualdades estas que extrapolam os indicadores socioprofissionais aportados em marcadores de diferença e na essencialização das experiências do gênero, pois ligadas ao modo como as relações tecidas no ambiente das redações refletem na reprodução de opressões que impactam mais fortemente os corpos dos sujeitos identificados como mulheres).

As seções seguintes do presente artigo serão dedicadas a esse objetivo. Inicialmente serão apresentados quatro vetores de análise das assimetrias de gênero que acometem as trajetórias das comunicadoras: a) no campo da divisão sexual do trabalho; b) nas culturas organizacionais; c) nas culturas profissionais; d) no seio das rotinas produtivas. Em seguida, as injustiças que afloram em cada uma dessas instâncias serão explicitadas por meio de dados oriundos de estudos precedentes, mas também pelos resultados da enquete "Desigualdade de gênero no jornalismo", conduzida em 2016 pelo Sindicato dos Jornalistas do Distrito Federal (SJPDF), e pelos resultados do relatório Violence and harassment against women in the news media: a global picture, divulgado em 2014 pela International Womens Media Foundation e pelo International News Safety Institute.

\section{Eixos investigativos}

Cumpre então explicitar os critérios adotados na segmentação em quatro esferas das desigualdades experimentadas pelas jornalistas no exercício da profissão. Tal subdivisão proposta se justifica na própria literatura de referência da área, muito embora em outras categorias profissionais as mulheres também sofram com as consequências de uma rígida divisão sexual do trabalho ou das opressões de uma cultura organizacional machista.

\footnotetext{
${ }^{4}$ Conforme Damian-Gaillard et al. (2009) e Steiner (2014), muitas das categorias que se tornaram historicamente desprestigiadas passaram também a receber em volume expressivo de mulheres em seus quadros funcionais, frequentemente exercendo os cargos mais precários do setor.
} 
Não obstante, no que tange especificamente ao campo jornalístico, Neveu (2000), amparado pela perspectiva de Pierre Bourdieu, já frisara a influência da divisão sexual do trabalho na prescrição assimétrica dos vínculos empregatícios em empresas jornalísticas ou mesmo no precoce abandono da profissão por parte das mulheres impelidas a conciliarem forçosamente suas jornadas com uma sobrecarga de atividades domésticas e familiares.

Já a diferenciação entre culturas organizacional e profissional é inspirada em argumento de De Bruin (2000). A autora recupera a história dos estudos de mídia no ímpeto de evidenciar a importância conferida à etnografia das empresas de comunicação no início dos anos de 1970. Originadas de um viés funcionalista (a empresa como uma entidade neutra encarregada de uma atribuição social), as incursões nesse domínio foram se refinando para levar em consideração, por exemplo, assimetrias de gênero manifestas na segregação vertical dos cargos, conferindo às mulheres funções de menor prestígio (NILSSON, 2010) ou ainda a circulação e enaltecimento de valores machistas na estrutura organizacional (DE BRUIN, 2014). Para De Bruin (2000), a identidade organizacional é "conectada a um 'território' cultural e espacial - nesse caso, as organizações jornalísticas - e é levada a cabo por aqueles que tomam parte nessa organização, na medida em que permanecem nela" (p. 229). Já as identidades profissionais, prossegue a autora,

referem-se a um quadro amplo de referências - uma ideologia - não necessariamente dirigidas pelos membros de uma organização claramente identificável, mas sim por uma comunidade imaginada, que se estende por todas as organizações. Mudar-se de uma empresa específica não implica necessariamente no fim de uma identidade profissional; entretanto, usualmente corresponde ao fim de certa identidade organizacional (DE BRUIN, 2000, p. 229).

À vista disso, a cultura profissional jornalística é sedimentada pelos princípios e códigos que regem o ofício. Muito embora eles frequentemente não sejam generalizáveis e por vezes até se tornem conflitantes quando contrastados por regiões do globo, ainda assim é possível afirmar a existência de uma identidade profissional que delineia o campo (HANITZSCH; HANUSH, 2012), e que também se torna uma zona de profusão de desigualdades às comunicadoras, nomeadamente segregações horizontais (DAMIAN-GAILLARD et al., 2009).

Por fim, as rotinas produtivas são, como pontua Einat LACHOVER (2005), a via de análise menos explorada pelas investigações que se dedicaram a perscrutar as injustiças que acometem as mulheres repórteres. A invisibilização desta forma de manifestação das desigualdades no mundo do trabalho dos jornalistas, mesmo em investigações supostamente sensíveis às questões de gênero, torna os pesquisadores e pesquisadoras cegos ao fato de que, seja na apuração de informações, no contato com fontes ou mesmo participando de acontecimentos sociais, as mulheres são frequentemente (e relacionalmente) qualificadas por estereótipos de gênero que prejudicam sua integridade moral e física ou, mesmo, adicionam obstáculos injustos que dificultam a realização de suas atividades enquanto jornalistas. Refiro-me aqui especificamente aos estudos empíricos supracitados que tematizam o gênero descritivamente como indicador para avaliação quantitativa da intensificação da precariedade no setor ou a "feminização da imprensa" como fenômeno potencialmente capaz de subverter culturas organizacionais e profissionais enraizadas nas redações.

Nas próximas seções pretende-se delinear um quadro sistematizado das assimetrias às quais as jornalistas estão sujeitas nos mercados de mídia, quadro este que evidentemente será ampliado ou revisado a partir de estudos subsequentes, mas que a despeito disto pode servir de referência às pesquisas empíricas dedicadas a rastrear, via expedição etnográfica, desigualdades que afetam as mulheres inseridas no mundo do trabalho dos jornalistas.

\section{Divisão sexual do trabalho}

No debate sobre as reestruturações produtivas que atingem o mundo do trabalho dos comunicadores, frequentemente se menciona o atrelamento da deterioração das condições laborais desses profissionais à extensão das jornadas de trabalho para além do regulamentado pelos dispositivos da Consolidação das Leis do Trabalho (CLT), às demissões em massa em diversos veículos da grande imprensa e à flexibilização dos vínculos empregatícios. Nesse panorama pintado com cores sombrias pelos estudiosos e estudiosas da área e vivenciado sob um misto de pressão e sofrimento pelos jornalistas, inserir a divisão sexual do trabalho como um componente adicional de precariedade no setor é fundamental para refletir sobre obstáculos exclusivos às mulheres que paulatinamente se aventuram na profissão.

Um primeiro aspecto a ser ressaltado em nível global é a dificuldade vivenciada pelas repórteres em conciliarem o exercício de suas funções (em uma carreira que vem exigindo sacrifício acentuado dos tempos de descanso) com seus projetos familiares. Neveu (2000) já havia diagnosticado esse processo em cenário francês na virada do século XXI quando menciona os custos proibitivos do engajamento profissional às jornalistas "sobre suas vidas privadas e familiares, e a destruição das relações pessoais em consequência" (NEVEU, 2000, p. 201) - custos impraticáveis para mulheres com filhos, por exemplo. 
Tabela 1 - Vetores de expressão das desigualdades de gênero no jornalismo

\begin{tabular}{l|l}
\hline 1. Divisão sexual do trabalho & $\begin{array}{l}\text { A) Dupla jornada de trabalho inconciliável com a } \\
\text { intensificação dos fluxos de produção jornalística; } \\
\text { B) Predominância de profissionais jovens, solteiras e sem } \\
\text { dependentes. } \\
\text { C) Discriminação sofrida por mulheres casadas e com } \\
\text { filhos. } \\
\text { D) Tendência de flexibilização dos contratos de trabalho } \\
\text { no intuito de conciliar a dupla jornada. } \\
\text { E) Abandono precoce da carreira e dificuldade de } \\
\text { posterior reintegração aos quadros funcionais. }\end{array}$ \\
\hline
\end{tabular}

2. Cultura organizacional
A) Cultura organizacional que idealiza a figura masculina.

B) Segregação vertical.

C) Desigualdade salarial (a despeito de maior formação escolar).

D) Homossocialidade masculina.

E) Exercício de "rituais de reparação" em cargos de chefia.

F) Avaliação do desempenho tacitamente ancorada em gênero.

G) Avaliação profissional baseada em padrões estéticos, em produtos audiovisuais.

H) Intimidação, assédio e violência sexual.

I) Ausência de políticas para coibir casos de assédio nas empresas de comunicação.

\section{Cultura profissional}

\section{Rotinas produtivas}

Fonte: Autor.

A) Valores profissionais atrelados ao universo masculino. B) Maior prestígio atribuído aos profissionais do gênero masculino.

C) Segregação horizontal (por pautas, editorias, estilo de escrita).

D) "Neutralização" da expressão de gênero por mulheres que almejam não serem avaliadas em função de suposta "feminilidade" intrínseca.

A) Reprodução de binarismos de gênero nas redações. B) Intimidação, descrédito profissional, assédio e violência perpetrados por fontes de informação e entrevistados (sobretudo autoridades públicas, membros das elites financeiras e celebridades).

C) Hiperssexualização na relação com as fontes. D) Acesso restrito a determinados espaços e maior risco de sofrer violência na cobertura de acontecimentos públicos.

E) Intimidação e ameaça na interlocução com a audiência (sobretudo na cobertura de temas supostamente ligados ao universo masculino e em reportagens sobre questões de gênero e sexualidade). F) Silenciamento de profissionais vítimas de assédio.

G) Ausência de políticas nas empresas incumbidas de oferecerem amparo psicológico e jurídico às profissionais.

No contexto brasileiro, há uma predominância (sustentada por investigações sobre o perfil do jornalista em exercício no país) de repórteres mulheres solteiras e sem dependentes em relação às casadas e com filhos. Em questionário aplicado em 1998 com 402 jornalistas de São Paulo, Herscovitz (2000) já apontara que "as mulheres tendem a ser um pouco mais jovens que os homens, com idade média de 34 anos, e há mais solteiras do que solteiros $(49,1 \%$ das mulheres contra $35,5 \%$ dos homens)" (p. 69). Adiante, arremata a autora: "só $3 \%$ das mulheres ocupam cargos de 
alta responsabilidade nas redações e seus salários são inferiores aos dos homens" (HERSCOVITZ, 2000 , p. 69). Mais de uma década a posteriori da publicação deste trabalho, Lima (2012) e Fígaro $(2013 ; 2014)$ reforçam a tendência supramencionada ao perscrutar o perfil médio do jornalista que atua em São Paulo (delineado após questionário aplicado com 538 participantes, além de entrevista com 20 colaboradores): "jovens, brancos, de classes médias, mulheres (a maioria sem filhos), multiplataformas, vínculo de emprego precário, com curso superior completo e com especialização em nível de pós-graduação" (FíGARO, 2013, p. 8). Por fim, em survey empreendido em escopo nacional com 2731 comunicadores, Mick e Lima (2013) concluem: em média 64\% dos jornalistas são mulheres e $59 \%$ se encontram na faixa de até 30 anos.

Essa inclinação do mundo do trabalho dos jornalistas para receber mulheres solteiras e sem dependentes também se manifesta no alto escalão das redações em aspecto global: em contexto sueco, por exemplo, Djerf-Pierre (2005) assinala que, enquanto $92 \%$ dos homens em posições de chefia em empresas de comunicação locais são casados e com filhos, somente $72 \%$ das mulheres estão em patamar similar. ${ }^{5}$ Os resultados são reforçados em cenário norte-americano, conforme indica Steiner (2014) ao apontar que $90 \%$ dos homens e tão somente $65 \%$ das mulheres em cargos de chefia em veículos de mídia possuem filhos (e as mulheres tendem a retardar a decisão de terem crianças duas vezes mais que os seus colegas do gênero masculino).

Há que salientar também a discriminação sofrida por mulheres casadas e com dependentes no ambiente das redações jornalísticas, como já documentado pela literatura (SANTOS; TEMER, 2016; LEITE, 2017). O levantamento promovido pelo Coletivo de Mulheres Jornalistas do Sindicato dos Jornalistas Profissionais do Distrito Federal ratifica essa prática: das 535 participantes da pesquisa, $46 \%$ afirmaram conhecer colegas que sofreram preconceito da equipe de trabalho enquanto estavam grávidas.

Na pesquisa empreendida por Leite (2017) com jornalistas que residem e exercem suas atividades na cidade de São Paulo, as entrevistadas destacam a criação dos filhos como o elemento mais inconciliável com as jornadas de trabalho. As interlocutoras com dependentes também mencionam terem sofrido preconceito quando precisaram abandonar suas atividades para se dedicarem aos cuidados emergenciais com as crianças.

Uma vez que as mulheres assumem a gestão das atividades domésticas com maior frequência que os homens, é mais recorrente que se submetam a contratos flexíveis e intermitentes no intuito de adequarem suas tarefas profissionais à dupla jornada de trabalho (STEINER, 2014; SANTOS; TEMER, 2016). Isso corresponde a um enxugamento ainda mais expressivo dos tempos de lazer, com sobrecarga de responsabilidades e acentuação de desgaste físico e psicológico. Segundo dados da Pesquisa Nacional de Amostra por Domicílios (PNAD) de 2015 (IBGE, 2016), no Brasil as mulheres gastam em torno de 10 horas a mais que os homens em trabalhos domésticos: suas jornadas semanais (somando o trabalho principal às atividades domésticas) correspondem a 50,4 horas, ao passo que os homens trabalham em média 50,8 horas. No mercado jornalístico, o impacto desta sobrecarga é que, para muitas profissionais, conforme Leite (2017), a atividade de freelancer por vezes acaba sendo compulsória, sobretudo no caso de mulheres com dependentes que precisam compatibilizar seus horários de trabalho com a rotina das crianças.

Resultados do relatório Violence and harrassment against women in the news media: a global picture (2014) assinalaram que, das 977 participantes do survey aplicado com mulheres jornalistas de cinco continentes, quase um terço se declarou exclusivamente freelancer $(27,4 \%) .{ }^{6}$ Na França, Denis RUELLAN (2001) e Damian-Gaillard et al. (2009) também enfatizaram essa tendência, contrastando a maior formação das ingressantes na carreira com sua trajetória marcada mais acentuadamente por contratos instáveis e precários. Assim, mesmo com maior bagagem acadêmica que os jornalistas homens, as mulheres são penalizadas tão logo ingressam no setor (fenômeno também destacado na pesquisa supracitada de Leite (2017)).

Para além da maior instabilidade no setor, as mulheres jornalistas também estão mais predispostas a abandonarem seus empregos para se dedicarem exclusivamente às atividades reprodutivas (RUELLAN, 2001; DAMIAN-GAILLARD et al., 2009; STEINER, 2014; LEITE, 2017) e sofrem mais entraves quando anseiam se reintegrar aos quadros funcionais (LEITE, 2017). Este fenômeno é também percebido em outros campos de atuação profissional: se nos basearmos novamente nos dados da PNAD para 2015 (IBGE, 2016), a taxa de desocupação geral foi de $9,6 \%$, mas ao tomar o gênero como característica selecionada, percebe-se que o índice de mulheres desempregadas foi de $11,7 \%$, enquanto que para os homens a estimativa era de $7,9 \%$.

\footnotetext{
${ }^{5}$ Isto, pois, segundo a autora (DJERF-PIERRE, 2005), os profissionais do gênero masculino casados mais recorrentemente possuem o amparo de uma mulher que assume as atividades reprodutivas no ambiente familiar (e muitas companheiras de executivos de mídia trabalham em regime parcial ou se dedicam exclusivamente às atividades domésticas). ${ }^{6}$ Enquanto que $52,1 \%$ possuíam contratos formais, $17,6 \%$ exerciam suas funções como contratadas e freelancers, e $6 \%$ alegaram atuar com outros vínculos empregatícios.
} 


\section{Cultura organizacional}

A despeito da sociologia das profissões por muito tempo ter retratado as organizações de um viés funcionalista, ou seja, como organismos "neutros" às questões de gênero (DE BRUIN, 2000; DAMIAN-GAILLARD et al., 2009), não só no jornalismo, mas também em outras esferas do mundo do trabalho, há sensíveis desigualdades no âmbito dessas culturas empresariais que produzem, na esteira, uma miríade de segregações verticais.

Alguns estudos apontaram que as culturas organizacionais no jornalismo são campos dominados por valores machistas, nos quais as mulheres são frequentemente tratadas pelos seus colegas e chefes com um tom paternalista (ROCHA, 2007) ou, ainda, desprivilegiadas na divisão de tarefas por não se enquadrarem nos modelos de masculinidade idealizados na redação (NEVEU, 2000; NILSSON, 2010; DE BRUIN, 2014). Em etnografia em programa jornalístico de uma TV pública sueca, Nilsson (2010) ainda assinala outro componente nocivo à integração das mulheres na instituição: a homossocialidade masculina, não assumida pelos homens entrevistados pela autora, mas explícita na inclinação deles em atribuírem as pautas de maior destaque a colegas do mesmo gênero, bem como partilharem contatos e informações exclusivamente entre si. Ademais, as mulheres repórteres eram constantemente julgadas por supostas características intrínsecas à sua "condição feminina" que trariam prejuízos à sua atuação profissional.

Outro traço global das desigualdades atreladas aos marcadores de gênero no que diz respeito às culturas organizacionais é a disparidade salarial. Na França, mesmo com maior formação, as mulheres jornalistas recebem remuneração inferior nas redações, como indicam Damian-Gaillard et al. (2009). No Brasil, fenômeno similar ocorre, como apontam Rocha e Sousa (2011) e Leite (2017). No survey empreendido por Mick e Lima (2013), detectou-se que as mulheres representaram a maior faixa do estrato até cinco salários mínimos, e a minoria em todos os segmentos com remuneração superior a esse montante. Acrescentam Rocha e Sousa (2011) que "a desigualdade de remunerações aumenta em proporção ao nível de escolaridade; assim, quanto mais elevada é a escolaridade, maior é a diferença entre homens e mulheres" (p. 12). Mais adiante, arrematam: "A mulher com curso superior recebe, em geral, o equivalente a um homem com segundo grau. A feminização ainda ocorre em maior número em áreas menos prestigiadas ou mais recentes" (ROCHA; SOUSA, 2011, p. 16-17).

É fundamental pontuar que o vínculo entre maior formação educacional e disparidade salarial não é exclusivo ao campo jornalístico, e diz respeito, ao menos em cenário nacional, à realidade da inserção da mulher no mercado de trabalho. Conforme dados da PNAD de 2015 (IBGE, 2016), o rendimento médio dos brasileiros era de $\mathrm{R} \$ 1.808,00$, mas a média salarial dos homens correspondia a R\$2.012,00, enquanto que as mulheres tinham remuneração média de $\mathrm{R} \$ 1.522,00$, ou seja, $75 \%$ do valor. Este desequilíbrio salarial eleva-se na medida em que o grau de escolaridade é levado em consideração: se entre os trabalhadores com até quatro anos de estudo as mulheres recebem menos de $R \$ 1,00$ por hora a menos que os homens, para profissionais com mais de 12 anos de estudo esta diferença atinge R\$ 13,00 por hora. Em cargos de gerência, homens recebem em média $\mathrm{R} \$ 5.222,00$, enquanto que as mulheres ganham $\mathrm{R} \$ 3.575,00$.

No levantamento "Desigualdades de Gênero no Jornalismo" (SJPDF), dentre as 535 jornalistas de vários Estados que foram indagadas nos seguintes termos: "Você já esteve em alguma situação que seu colega recebia um salário maior que o seu, mesmo desempenhando igual função?", $61,5 \%$ responderam afirmativamente. A disparidade nos indicadores articula-se a outra assimetria já fartamente documentada na literatura global: a diminuta fração de mulheres na categoria que consegue alcançar cargos de chefia nas empresas em que atuam. O fenômeno é proeminente em países como a França (NEVEU, 2000; RUELLAN, 2001; DAMIAN-GAILLARD et al., 2009), a Suécia (DJERF-PIERRE, 2005; NILSSON, 2010), os Estados Unidos (STEINER, 2014), mas também Portugal (ROCHA; SOUSA, 2011) e Brasil (HERSCOVITZ, 2000; FÍGARO, 2014).

Steiner (2014) acentua como o gênero exerce influência negativa nas avaliações de desempenho de gestoras: falhas são diretamente associadas a uma suposta "feminilidade" intrínseca que preponderante ao cargo, enquanto que para os homens não existe qualquer junção desfavorável entre suas competências técnicas e sua masculinidade. Ademais, para a autora, se a conduta das chefes "confirma os estereótipos acerca das mulheres, elas não são vistas como líderes apropriadas; se o seu comportamento é consistente com os estereótipos de liderança, elas não são pensadas como mulheres adequadas" (STEINER, 2014, p. 626).

Um fenômeno registrado em algumas incursões empíricas (como a de Nilsson (2010) no telejornal de uma emissora pública sueca, e nas investigações de Rocha (2007) e Leite (2017) com jornalistas paulistas), é a emulação dos ideais de gestão machistas por parte das mulheres que ocupam cargos de chefia na imprensa, evitando ao máximo o tensionamento das desigualdades no ambiente organizacional. Para Rocha (2007), há "a necessidade da chefe incorporar um estilo masculino para exercer o poder. É preciso masculinizar a função de comando para ser respeitada. A falta de poder, na forma como a mulher é vista, exige dela o uso de mais força para [...] impor-se" (p. 131). Leite (2017), a seu turno, cita também o caso de editoras que relatavam "comportar-se 
como homens", esquivando-se de possíveis críticas ligadas à sua suposta feminilidade intrínseca. Outra prática corrente, explicitada por Nilsson (2010), é o assédio e a rispidez de gestoras com suas subordinadas, evitando assim serem taxadas de feministas ou como "facilitadoras" do trabalho de outras mulheres. Nos termos de Nilsson (2010), "ao serem discretas e se voltarem para os homens (sendo heterossociais), algumas líderes femininas praticam rituais de reparação no intuito de reestabelecer a ordem simbólica que haviam rompido" (p. 12).

A violência e o assédio sofridos por comunicadoras também são outro aspecto alarmante das injustiças que afetam mulheres no exercício da profissão, como atesta uma série de investigações dedicadas à questão (LACHOVER, 2005; ROCHA, 2007; JORGE; ADGHIRNI, 2013; STEINER, 2014). O relatório da International Women's Media Foundation (2014) oferece uma vasta lista de desrespeitos sofridos em ambientes organizacionais pelas repórteres, devidamente acompanhados de seus respectivos indicadores percentuais: $64,8 \%$ das participantes declararam terem sido alvos de abuso de poder, intimidação verbal ou escrita e ameaças de difamação e humilhação na empresa em que foram contratadas, sobretudo no espaço físico da redação. Em $31,7 \%$ dos casos em que o perpetrador foi mencionado se tratava de um chefe. $63,6 \%$ dos agressores citados eram homens. Casos de assédio moral foram destacados por quase metade das participantes (47,9\% da amostra), a maioria deles ocorrendo na redação $(42,2 \%$ do total). Mais da metade dos ofensores eram colegas e superiores $(55,3 \%)$, e em $93,8 \%$ dos casos tratavamse de homens.

Por fim, no tocante à violência sexual no trabalho, 14,3\% das jornalistas entrevistadas pela pesquisa assinada por Alana BARTON e Hannah STORM (2014) indicaram terem sido indevidamente tocadas por chefes e/ou colegas, enquanto outras foram expostas a atos obscenos e vítimas de estupro. Em $24,5 \%$ dos casos a agressão ocorreu na redação, sendo que $18,9 \%$ delas foram cometidas por colegas e 15,3\% por chefes e supervisores. Em 95,6\% das ocorrências registradas no survey que mencionaram o gênero do perpetrador, este se tratava de um homem. Em contexto nacional, os dados do levantamento realizado em 2016 pelo Sindicato dos Jornalistas Profissionais do Distrito Federal com comunicadoras brasileiras repercutem os resultados em nível global: das 535 respondentes, $77,9 \%$ alegaram terem sofrido assédio da chefia ou de colegas de empresa.

Não obstante o assédio e a violência ao qual estão submetidas as mulheres jornalistas em ambiente organizacional (e que se agravam em regiões interioranas, como salienta Rocha (2007)), em alguns veículos (sobretudo no telejornalismo) as comunicadoras também são julgadas segundo sua conformação aos padrões estéticos vigentes, de tal modo que "mulheres negras, gordas ou tidas como feias encontram mais dificuldades de ingressarem no mercado de trabalho como repórteres em emissoras de televisão" (ROCHA, 2007, p. 129-130). A etnografia empreendida por Silva (2013) na redação de um telejornal da RBS TV, em Porto Alegre, é exemplar nesse sentido: a bancada do programa era composta por dois apresentadores, uma mulher e um homem, ambos veteranos na empresa. O amadurecimento deles gerou, para o jornalista, um acréscimo de prestígio e autoridade no veículo, enquanto que, para a colega, o resultado foi a exoneração do cargo, informalmente justificada por seu sobrepeso e velhice.

Caberia pontuar, para encerrar a presente seção, a ausência de políticas nas empresas voltadas a coibir os casos de assédio e de desrespeito que permeiam as redações jornalísticas. Os dados do relatório Violence and harrassment against women in the news media: a global picture (2014) são novamente alarmantes: em contexto internacional, uma parcela diminuta das jornalistas afirma ter relatado casos de assédio, intimidação e violência nas organizações. $58,4 \%$ das vítimas de abuso e $32,7 \%$ das mulheres assediadas reportaram o caso aos seus superiores, mas as consequências ou foram nulas, ou motivaram uma demissão posterior da vítima, ou ainda promoveram uma escalada de agressões. Muitas inclusive foram desencorajadas a dar prosseguimento à denúncia por vias judiciais. Debruçadas na conjuntura nacional, Jorge e Adghirni (2013) sinalizam que só uma em cada 15 organizações de mídia brasileiras adota uma política de igualdade de gênero, e duas em 15 possuem códigos para reprimir o assédio nas redações.

\section{Culturas profissionais}

As culturas profissionais do campo jornalístico são amiúde descritas pela literatura especializada como construções simbólicas que operam a partir de uma perspectiva masculina imposta como norma (DAMIAN-GAILLARD et al., 2009). Conforme Leite (2017), "a figura do jornalista vista de uma forma abstrata, neutra, universal remete às categorias masculinas" (p. 16). Nesse sentido, os imaginários de isenção e imparcialidade valorizados pelos códigos deontológicos da área se aproximam muito mais facilmente de um habitus masculino, supostamente forjado na racionalidade e na retenção emocional (NEVEU, 2000). Para Nilsson (2010), as "hard news, as fontes masculinas, a posição de objetividade/neutralidade, e os critérios de qualidade e ética definidos pela profissão são apreendidos como parte de uma lógica 'masculina' dominante" (p. 1).

Se tais axiologias que privilegiam o masculino permeiam a formação dos comunicadores desde a Universidade (LEITE, 2017), as mulheres que atuam no setor veem-se obrigadas a entronizar 
uma cultura que de partida perturba suas possibilidades de autorrealização através da identificação profissional (DE BRUIN, 2000), uma vez que a "lógica feminina" é corriqueiramente associada nas redações às coberturas de menor relevância informativa (NILSSON, 2010). Seja em âmbito internacional (NEVEU, 2000; DAMIAN-GAILLARD et al., 2009) ou nacional (ROCHA, 2007; SILVA, 2013; LEITE, 2017), é fato largamente sustentado a alocação de jornalistas mulheres em editorias e pautas consideradas mais "brandas" (também nomeadas de soft news), tradicionalmente ligadas a assuntos culturais, fait-divers e aos aspectos estereotípicos da feminilidade (beleza, moda, entretenimento, maternidade, economia doméstica, comportamento) - notadamente de menor impacto na opinião pública. Diretores executivos e especialistas em marketing editorial habitualmente avaliam ser comercialmente rentável contratar jornalistas mulheres para assinarem matérias voltadas a temas apreciados como de interesse exclusivo ao público feminino, sob a vaga suposição de uma "sintonia" de preocupações (DAMIAN-GAILLARD et al., 2009; DAMIAN-GAILLARD; SAITTA, 2016).

Leite (2017) afirma que, em decorrência dessas práticas de setorização, "as matérias produzidas pelas mulheres têm muito menos chance de estarem estampadas na capa dos jornais, o que gera uma segregação vertical, na medida em que são atribuídos valores desiguais aos trabalhos produzidos por homens e por mulheres" (p. 54). A investigação empírica empreendida por Silva (2013) na redação de telejornalismo de um dos programas da RBS TV elucida de maneira satisfatória esse ponto: nas reportagens de cunho investigativo (que ganhavam manchete na escalada do programa), a autoria era exclusivamente masculina. "Na base da hierarquia estavam as soft news [...] que não previam um perfil especial de repórter, mas em geral eram concebidas para mulheres (ou homens reconhecidos por fazerem matérias 'não sérias'), e eram exibidas nos demais blocos, de menor audiência" (SILVA, 2013, p. 100). Ademais, muito embora a apresentação do programa fosse dividida por um homem e uma mulher (ambos editores-chefes do noticiário em questão), o profissional do gênero masculino gozava de mais autonomia, prestígio e autoridade na delegação de tarefas aos seus colegas. Normalmente, a essa editora-chefe eram destinadas exatamente as matérias "leves, divertidas, 'femininas', sem status de hard-news" (SILVA, 2013, p. 101). Para a autora, o que promovia a não contestação dessa forma de segregação era, sobremaneira, o fato de que tanto homens quanto mulheres partilhavam na redação os mesmos valores e expectativas de gênero, de tal modo que a própria editora-chefe em tela assumia que jornalistas afeitos ao tipo-ideal profissional eram mais aptos a efetuarem a cobertura de determinadas pautas.

Novamente conforme Leite (2017), uma estratégia para contornar as desigualdades no plano das culturas profissionais adotada por algumas jornalistas mulheres é a de "neutralizar" sua expressão de gênero, reservando-a ao universo da intimidade e da subjetividade. Em contrapartida, "os valores profissionais são exaltados por resultarem em maior reconhecimento da profissional, 0 que conduz as mulheres a reforçarem sua identidade profissional em detrimento da de gênero, que estaria ligada a estereótipos negativos" (LEITE, 2017, p. 62).

\section{Rotinas produtivas}

Ełnografias em redações, como a empreendida por Silva (2011), já destacaram, na própria elaboração das pautas, a reprodução de um sistema de binarismos de gênero que conduz o newsjudgment dos jornalistas quando realizam a cobertura de determinados acontecimentos sociais. Contudo, o aspecto mais bem documentado que sinaliza para as injustiças sofridas pelas repórteres em suas rotinas produtivas diz respeito às suas relações com as fontes (elemento central da apuração noticiosa). Em nível internacional, $64,8 \%$ das mulheres afirmam ter experimentado assédio, intimidações ou ameaças em seu trabalho, tendo os entrevistados como os principais perpetradores (BARTON; STORM, 2014). Em 63,6\% dos casos registrados pelo relatório da International Women's Media Foundation (2014) o assediador tratava-se de um homem. A recorrência dos casos fez com que muitas das participantes do questionário relatassem que o assédio era inevitável em sua rotina de trabalho.

Já no que tange à violência sexual, o mesmo estudo aponta que 14,3\% das respondentes sofreram agressão dessa natureza no exercício de suas atividades (variando da exibição de órgãos genitais por parte do entrevistado ao estupro propriamente dito). Em 95,6\% dos casos em que o gênero do agressor foi mencionado, tratava-se mais uma vez do masculino (BARTON; STORM, 2014). Os resultados em espectro global são corroborados em nível nacional: das 535 mulheres jornalistas que responderam o levantamento "Desigualdade de Gênero no Jornalismo" (SJPDF), $47,5 \%$ alegaram já terem sofrido violência de gênero em coberturas jornalísticas, e 78,5\% informaram terem sido vítimas de atitudes machistas de entrevistados.

Como pontuado por Leite (2017), ao entrevistar autoridades públicas, as mulheres jornalistas são desqualificadas, ouvem piadas machistas, são enquadradas em estereótipos de gênero, e, por vezes, precisam ocultar seus atributos físicos para serem respeitadas. Segundo diagnóstico do documento Violence and harrassment against women in the news media: a global picture (2014), 
repórteres assediadas pelas fontes frisam que a prática é corriqueira no contato com membros de instituições públicas, e variam do desrespeito e da intimidação verbal às ameaças de encarceramento, difamação, chantagem, vigilância forçada e sequestro de familiares. Cabe ressaltar que o assédio experimentado por mulheres jornalistas no contato com fontes não se restringe à relação com autoridades públicas, e pode ser estendido a figuras dotadas de poder simbólico e financeiro em geral, como celebridades e empresários.

No intuito de evitarem assédios que podem ocorrer de maneira sutil ou explícita, algumas jornalistas optam por manterem uma distância de campos sociais nos quais a prática é recorrente (como o campo político, o esportivo, o policial etc.), com o ônus de se verem frequentemente apartadas da cobertura noticiosa nesses espaços (NEVEU, 2000; DAMIAN-GAILLARD; SAITTA, 2016), algo que pode acontecer também por determinação da chefia: 70,7\% das entrevistadas pela enquete realizada em 2016 pelo SJPDF alegaram já terem sido dispensadas pelos seus superiores de determinadas pautas por serem mulheres.

Essa precaução, acompanhada de severa restrição à autonomia profissional, é também corriqueira na cobertura de acontecimentos sociais que mobilizam grandes aglomerações (como protestos ou passeatas), bem como em zonas de conflito bélico. O relatório da International Women's Media Foundation (2014) acentua que mais de um terço das jornalistas $(38,7 \%)$ que foram vítimas de violência sexual sofreram a agressão em espaços públicos, ao passo que $21,6 \%$ foram fisicamente atacadas no trabalho. Desse percentual, $45,5 \%$ alegaram terem sido agredidas por estranhos em zonas urbanas. Dos incidentes em que o gênero do perpetrador foi identificado, em $77,2 \%$ dos casos tratava-se de um homem. O relatório ainda destaca que muitas das profissionais vítimas de violência durante coberturas jornalísticas passaram a evitar noticiar acontecimentos que poderiam lhes oferecer riscos similares ou adotaram medidas adicionais para garantir sua segurança, enquanto outras foram desencorajadas por seus colegas e superiores a prosseguirem escrevendo sobre esses temas (BARTON; STORM, 2014).

Debruçada em apreender, no contexto israelense, as relações entre jornalistas mulheres e suas fontes de gênero masculino, Lachover (2005) explora outra faceta desses contatos habitualmente permeados por assédio e discriminação. Relatando serem corriqueiramente enquadradas por seus interlocutores em três estereótipos de feminilidade (objeto sexual; profissionais incapazes e/ou indefesas; figuras maternais), muitas das 32 repórteres entrevistadas pela autora alegaram adotar a estratégia de aderirem às expectativas das fontes no intuito de conseguirem exercer seu ofício (ao invés de neutralizarem suas características femininas). Em outros termos, ao investirem na tensão sexual provocada pelo assediador ou ainda simularem uma atitude indefesa que instiga o paternalismo dos entrevistados, as comunicadoras não só conseguiam obter informações às quais não teriam acesso caso assumissem uma postura combativa em face da injustiça vivenciada, ${ }^{7}$ bem como se sentiam menos vulneráveis: "enfatizando seu autocontrole e o que percebem como um poder sobre o assediador, elas podem escolher entre reagir ao assédio ou ignorá-lo" (LACHOVER, 2005, p. 298). Mas a despeito das aparentes vantagens proporcionadas por táticas dessa natureza (como escamotear o sofrimento ou contornar obstáculos ao exercício do jornalismo), Lachover (2005) pondera que a prática tem "impacto mínimo na mudança de percepções sociais mais amplas sobre como o poder calcado em gênero é ou 'deveria' ser distribuído na sociedade" (p. 309).

Saltando da interlocução com as fontes de informação para as relações com os leitores dos veículos para os quais prestam serviços, também é nítida a misoginia e o tom ameaçador presentes nos comentários de matérias assinadas por mulheres em portais de notícias on-line, fenômeno que intimida muitas profissionais e exerce um impacto negativo em suas carreiras. Tomando por referência o contexto sueco (país considerado progressista no tocante à igualdade de gênero), Nilsson e Henrik ÖRNENBRING (2016) constatam que um terço das jornalistas que participaram de um survey com 1.936 comunicadores locais declararam terem recebido comentários sexistas da audiência e em torno de 15\% foram ameaçadas de estupro, mutilação genital e outras formas de violência sexual. A incidência de casos é maior em resposta aos textos de colunistas e, sobretudo, quando os temas debatidos na reportagem envolvem o feminismo e questões de gênero e sexualidade ( $16 \%$ dos respondentes alegaram ter sido esse o gatilho para as ofensas). Conforme as autoras, "a intimidação e o assédio constituem uma via efetiva para silenciar jornalistas, mesmo no contexto de sociedades democráticas estáveis, como a Suécia" (NILSSON; ÖRNENBRING, 2016, p. 10), uma vez que há uma ligação estreita entre a autocensura e a reincidência de insultos de leitores. Os dados do survey de Barton e Storm (2014) confirmam esses resultados, apontando que $25 \%$ das profissionais que participaram do relatório global assinado por elas afirmaram terem sofrido assédio em ambiente on-line (não só por meio de comentários da audiência, mas também por mensagens diretas via e-mail, Facebook e Twitter), algo que as desencorajou a realizarem determinadas coberturas.

${ }^{7}$ Lachover (2005) também pontua que essa conduta assumida por muitas de suas entrevistadas recebia aprovação da chefia, que a avaliava como um meio eficaz de conseguir notícias exclusivas. 
O silenciamento de comunicadoras vítimas de assédio é uma forte tendência em âmbito internacional, e deriva, sobretudo, da ausência de políticas nas redações incumbidas de oferecerem amparo psicológico e jurídico às profissionais (carência já mencionada no tocante ao desrespeito gerado em ambiente organizacional). Mais uma vez, conforme dados da International Women's Media Foundation (2014), 80,7\% das profissionais vítimas de violência sexual não comunicaram a ocorrência a ninguém e somente $35 \%$ das jornalistas que sofreram agressão física relataram o caso a alguma autoridade. Desse percentual, 51,5\% reportaram à chefia, mas na maior parte dos incidentes não houve qualquer suporte ou acolhimento da empresa. 69,8\% das respondentes informaram não terem recebido qualquer treinamento para aumentar sua segurança pessoal, ao passo que 77,2\% também não obtiveram capacitação em proteção online (BARTON; STORM, 2014). Cabe salientar, por fim, que em muitas situações a publicização da violência sofrida pode inclusive acarretar dano adicional às vítimas (assim como ocorre nos casos de assédio em contexto organizacional).

\section{Considerações finais}

Ao discorrer sobre algumas das múltiplas expressões (cotejadas por dados de escopo global e nacional) de assimetrias que impactam a trajetória de mulheres jornalistas no exercício de suas atividades profissionais, procurei cartografar um mapa parcial das injustiças que perpassam as carreiras de comunicadoras inseridas nessa esfera do mundo do trabalho - injustiças estas apresentadas de modo difuso ou mais recorrentemente negligenciadas em análises dedicadas a delinear a deterioração das condições laborais na grande imprensa. Os resultados sinalizam que as iniquidades que afligem as jornalistas excedem os indicadores quantitativos de disparidade salarial ascendente em função do grau de escolaridade, obstrução ao acesso a postos de chefia nas redações, propensão à desocupação precoce em cargos na mídia ou mesmo abandono da carreira decorrente da tendência à contratação em regime flexível como meio de conciliar a dupla jornada de trabalho (que acomete mulheres nos mais distintos campos profissionais). Como este trabalho procurou evidenciar, há um expressivo volume de arbitrariedades que impacta negativamente as carreiras das comunicadoras e que não são detectáveis em investigações sociodemográficas porque dizem respeito à experiência qualitativa do gênero em uma sociedade marcadamente sexista-a exemplo da discriminação sofrida por mulheres casadas e com filhos em empresas de mídia, a idealização da masculinidade nas culturas organizacional e profissional, a segregação horizontal, a avaliação de desempenho calcada em padrões estéticos, além da intimidação, do assédio e da violência sexual.

É preciso ainda constatar que a invisibilidade de muitas destas formas de desrespeito que perturbam as trajetórias das jornalistas não é só patente no campo da sociologia das profissões, uma vez que se perpetua mais agressivamente na sistemática recusa por parte das empresas de mídia em incluírem políticas de repressão às práticas de assédio e de oferecerem assistência às mulheres por meio de treinamento e assistência psicológica e jurídica. A falta de diligência diante destas diversas formas de desrespeito é terreno fértil para sua naturalização.

Mas o tom sobremaneira alarmante e crítico dessa excursão não deve ser interpretado, todavia, como meio de relativizar a combatividade das comunicadoras, como se elas fossem vítimas indefesas em um universo hostil. Se o problema que orienta este trabalho concerne, sobretudo, à insensibilidade dos estudos situados no campo da sociologia do jornalismo às questões de gênero, não se deve perder de vista que no plano empírico as profissionais dos diversos ramos da imprensa vêm gradualmente questionando as desigualdades e violências que perpassam sua trajetória no setor, vocalizando suas demandas e expondo à opinião pública as injustiças que sofrem no exercício de suas atividades ${ }^{8}$ - mesmo em um panorama de acentuadas demissões nas empresas de mídia. Contudo, até o presente momento estas ações não conduziram a uma revisão dos padrões opressivos que perduram nas organizações com vistas à ampliação da igualdade de gênero nas redações brasileiras.

É fundamental que não confundamos as reações das mulheres jornalistas às injustiças que as afetam diariamente no mundo do trabalho com a ilusória euforia de que a gradual feminização das redações conduz mecanicamente à isonomia de condições entre homens e mulheres no jornalismo, tal como defende uma seara de investigações dedicada a refletir com excessivo otimismo as consequências da crescente presença de comunicadoras nas empresas de mídia. Importante salientar uma vez mais que o alto percentual de mulheres jornalistas nas empresas de mídia não é capaz, per se, de subverter assimetrias solidamente enraizadas no tecido social, haja vista que, como muitos estudos detectaram, a naturalização e a reprodução das injustiças ligadas a gênero também são incorporadas por muitas mulheres nas redações como meio de permanecerem em seus postos ou mesmo de ascenderem em uma profissão que normatiza a

${ }^{8}$ A exemplo da campanha "Jornalistas contra o assédio", iniciada em 2016 por um coletivo de jornalistas brasileiras focadas em reportar e denunciar casos de assédio sofridos nas redações. 
figura masculina. Além disso, o risco deste desmedido entusiasmo em face da presença crescente de mulheres nas redações pode subestimar os nexos potenciais entre a precariedade de uma determinada esfera produtiva e sua paulatina feminização.

\section{Referências}

ADGHIRNI, Zélia. "Mudanças estruturais no jornalismo: travessia de uma zona de turbulência". In: PEREIRA, Fábio; MOURA, Dione; ADGHIRNI, Zélia (org.). Jornalismo e sociedade: teorias e metodologias. Florianópolis: Insular, 2012. p. 61-79.

BARTON, Alana; STORM, Hannah. Violence and harrassment against women in the news media: a global picture. Washington D.C.: International Women's Media Foundation, 2014.

BONETTI, Alinne. "Gênero, poder e feminismos: as arapiracas pernambucanas e os sentidos de gênero da política feminista". Labrys, Brasília, p. 1-16, 2012.

DAMIAN-GAILLARD, Béatrice; FRISQUE, Cégolène; SAITTA, Eugénie. "Le journalisme au prisme du genre: une problématique féconde”. Questions de communication, Metz, v. 15, p. 175-201, julho 2009.

DAMIAN-GAILLARD, Béatrice; SAITTA, Eugénie. "Feminização e transformações das práticas jornalísticas: o exemplo do jornalismo político na imprensa diária francesa". Parágrafo, São Paulo, v. 4, n. 2, p. 127-137, jul./dez. 2016.

DE BRUIN, Marjan. "Gender, organizational and professional identities in journalism". Journalism, Londres, v. 1, n. 2, p. 217-238, agosto 2000.

DE BRUIN, Marjan. "Gender and newsroom cultures". In: MONTIEL, Aimée (org.). Media and Gender: A Scholarly Agenda for the Global Alliance on Media and Gender. UNESCO, 2014. p. 41-46.

DJERF-PIERRE, Monika. "Lonely at the top: gendered media elites in Sweden". Journalism, Londres, V. 6, n. 3 , p. $265-290$, agosto 2005 .

DJERF-PIERRE, Monika. "The difference engine". Feminist Media Studies, Cardiff, v. 11 , n. 1, p. 43-51, março 2011.

FíGARO, Roseli. "Atividade de comunicação e trabalho dos jornalistas". E-Compós, Brasília, v. 16, n. 1, p. 1-20, jan./abr. 2013.

FÍGARO, Roseli. "Jornalismos e trabalho de jornalistas: desafios para as novas gerações do século XXI”. Parágrafo, São Paulo, v. 2, p. 23-37, jul./dez. 2014.

FONSECA, Virgínia. "Questões sobre a identidade do jornalista contemporâneo". Estudos em Jornalismo e Mídia, Florianópolis, n. 2, p. 129-140, jul./dez. 2008.

HANITZSCH, Thomas; HANUSCH, Folker. "Does gender determine journalists' professional views? A reassessment based on cross-national evidence". European Journal of Communication, Newcastle, v. 27, n. 3, p. 257-277, setembro 2012.

HELOANI, José. Mudanças no mundo do trabalho e impactos na qualidade de vida do jornalista. São Paulo: EDUFGV, 2005.

HERSCOVITZ, Heloiza. "Jornalistas de São Paulo: quem são e o que pensam em comparação aos jornalistas americanos e franceses". Intercom, São Paulo, v. 23, n. 2, p. 65-86, jul./dez. 2000.

IBGE. Instituto Brasileiro de Geografia e Estatística. Pesquisa nacional por amostra de domicílios: síntese de indicadores. Rio de Janeiro: IBGE, 2016. Disponível em https://biblioteca.ibge.gov.br/ visualizacao/livros/liv98887.pdf.

JORGE, Thaïs; ADGHIRNI, Zélia. "Brazil: need for national debate on Women in Journalism”. In: BYERLY, Carolyn (org.). The Palgrave International Handbook of Women and Journalism. New York: Palgrave Macmillan, 2013. p. 211-225.

JORGE, Thaïs; RAMALHO, Alzimar; RIBEIRO, Laís. "Mulheres no comando das redações: questões sobre a influência das mulheres jornalistas no processo de seleção de notícias". In: ENCONTRO NACIONAL DA ASSOCIAÇÃO BRASILEIRA DE PESQUISADORES EM JORNALISMO, $12^{\circ}$, Santa Cruz do Sul, Universidade de Santa Cruz do Sul, Associação Brasileira de Pesquisadores em Jornalismo. Anais do $12^{\circ}$ Encontro Nacional da Associação Brasileira de Pesquisadores em Jornalismo. Brasília: SBPJor, 2014, p. 1-16. 
KOFES, Suely. "Categorias analítica e empírica: gênero e mulher: disjunções, conjunções e mediações". Cadernos Pagu, Campinas, n. 1, p. 19-30, 1993.

LACHOVER, Einat. "The gendered and sexualized relationship between Israeli women journalists and their male news sources". Journalism, Londres, v. 6, n. 3, p. 291-311, agosto 2005.

LEITE, Aline. "Editoras, repórteres, assessoras e freelancers: diferenças entre as mulheres no jornalismo". Cadernos de Pesquisa, São Paulo, v. 47, n. 163, p. 44-68, jan./mar. 2017.

LIMA, Cláudia. "Formação, relações de trabalho e novos processos produtivos: o discurso de jovens jornalistas de São Paulo". Comunicação \& Inovação, São Caetano do Sul, v. 13, n. 25, p. 5360, jul./dez. 2012.

MARTINEZ, Monica; LAGO, Cláudia; LAGO, Mara. "Estudos de gênero na pesquisa em jornalismo no Brasil: uma tênue relação". FAMECOS, Porto Alegre, v. 23, n. 2, p. 1-23, maio/ago. 2016.

MICK, Jacques; LIMA, Samuel. Perfil do jornalista brasileiro. Características demográficas, políticas e do trabalho jornalístico em 2012. Florianópolis: Insular, 2013.

MORETZSOHN, Sylvia. "O 'novo ritmo da redação' de O Globo: a prioridade ao jornalismo digital e seus reflexos nas condições de trabalho e produção da notícia". Parágrafo, São Paulo, v. 2, p. 146165, jul./dez. 2014.

NEVEU, Érik. "Le genre du journalisme. Des ambivalences de la féminisation d'une profession". Politix, Paris, v. 13, n. 51, p. 179-212, jul./set. 2000.

NILSSON, Monica. "'Thinkings' and 'doings' of gender". Journalism Practice, Cardiff, v. 4, n. 1, p. 116, janeiro 2010.

NILSSON, Monica; ÖRNEBRING, Henrik. "Journalism Under Threat". Journalism Practice, Cardiff, p. 111, abril 2016.

PEREIRA, Fábio; ADGHIRNI, Zélia. "O jornalismo em tempo de mudanças estruturais". Intexto, Porto Alegre, v. 1, n. 24, p. 38-57, jan./jun. 2011.

PISCITELLI, Adriana. "Re-criando a (categoria) mulher?". In: ALGRANTI, Leila (org.). A prática feminista e o conceito de gênero. Textos Didáticos. Campinas: IFCH/Unicamp, 2002. p. 7-42.

ROCHA, Paula. "Mulher jornalista: relações familiares e profissionais". Comunicación y Cidadanía, Bogotá, n. 1, p. 119-134, jan./jun. 2007.

ROCHA, Paula; SOUSA, Jorge. "O mercado de trabalho feminino em jornalismo: análise comparativa entre Portugal e Brasil". Impulso, Piracicaba, v. 21, n. 51, p. 7-18, jan./jun. 2011.

RUELLAN, Denis. "Socialisation des journalistes entrant dans la profession". Quaderni, Paris, n. 45, p. 137-152, set./nov. 2001.

SANTOS, Marli dos; TEMER, Ana. "Jornalismo no feminino: a mulher jornalista, subjetividades e atuação profissional". Comunicação \& Sociedade, São Paulo, v. 38, n. 3, p. 35-58, set./dez. 2016.

SCOT, Joan. "Gênero: uma categoria útil de análise histórica". Educação \& Realidade, Porto Alegre, v. 15, n. 2, p. 71-99, jul./dez. 1995.

SILVA, Márcia. "A contribuição do jornalismo para a reprodução das desigualdades: um estudo etnográfico sobre a produção de notícias". Verso e Reverso, São Leopoldo, v. 25, n. 60, p. 183-192, set./dez. 2011.

SILVA, Márcia. "Uma história de Quitéria: refletindo sobre como os corpos 'pesam' no jornalismo". Vozes \& Diálogo, Itajaí, v. 12, n. 2, p. 96-109, jul./dez. 2013.

STEINER, Linda. "Glassy architectures in journalism". In: CARTER, Cynthia; STEINER, Linda; McLAUGHLIN, Lisa (org.). The Routledge Companion to Media and Gender. London and New York: Routledge, 2014. p. 620-631.

TEMER, Ana; ASSIS, Francisco; SANTOS, Marli dos. "Mulheres jornalistas e a prática do jornalismo de imersão: por um olhar sem preconceito". Media \& Jornalismo, Lisboa, v. 14, n. 15, p. 75-90, jan./jul. 2015. 
Thales Vilela Lelo (thales.lelo@gmail.com) é professor da Universidade do Estado de Minas Gerais - Unidade Divinópolis. Doutor em Ciências Sociais pela Universidade Estadual de Campinas. Mestre em Comunicação Social pela Universidade Federal de Minas Gerais. Membro do Grupo de Pesquisa em Jornalismo, Narrativas e Práticas Comunicacionais (UFOP) e do Grupo de Estudos em Trabalho, Saúde e Subjetividade (Unicamp), ambos certificados pelo CNPq.

\section{COMO CITAR ESSE ARTIGO DE ACORDO COM AS NORMAS DA REVISTA}

LELO, Thales Vilela. "A feminização do jornalismo sob a ótica das desigualdades de gênero". Revista Estudos Feministas, Florianópolis, v. 27, n. 2, e54225, 2019.

\section{CONTRIBUIÇÃO DE AUTORIA}

Concepção, coleta e análise de dados, elaboração do manuscrito, redação e discussão dos resultados

\section{FINANCIAMENTO}

A pesquisa recebeu financiamento do Conselho Nacional de Desenvolvimento Científico e Tecnológico (CNPq) via bolsa de Doutorado

CONSENTIMENTO DE USO DE IMAGEM

Não se aplica

APROVAÇÃO DE COMITÊ DE ÉTICA EM PESQUISA

Não se aplica

\section{CONFLITO DE INTERESSES}

Não se aplica

\section{LICENÇA DE USO}

Este artigo está licenciado sob a Licença Creative Commons CC-BY Internacional. Com essa licença você pode compartilhar, adaptar, criar para qualquer fim, desde que atribua a autoria da obra.

\section{HISTÓRICO}

Recebido em 24/1 1/2017

Reapresentado em 19/10/2018

Aprovado em 23/1 1/2018 